\title{
A machine learning model for screening of body fluid cytology smears
}

\author{
Parikshit Sanyal ${ }^{1}$, Sayak Paul $^{2}$, Vandana Rana ${ }^{3}$, Kanchan Kulhari ${ }^{3}$ \\ $1 \mathrm{MH}$ Jalandhar 2 Carted Inc 3 Command Hospital Panchkula
}

\section{Abstract}

Introduction: Body fluid cytology is one of the commonest investigations performed in indoor patients, both for diagnosis of suspected carcinoma as well as staging of known carcinoma. Carcinoma is diagnosed in body fluids by the pathologist through microscopic examination and searching for malignant epithelial cell clusters. The process of screening body fluid smears is a time consuming and error prone process.

Aim: We have attempted to construct a machine learning model which can screen body fluid cytology smears for malignant cells.

Materials and methods: MGG stained Ascitic / pleural fluid cytology smears were included from 21 cases (14 malignant, 07 benign) in this study. A total of 693 microphotographs were taken at 40x magnification at the same illumination and after correction of white balance. A Magnus Microphotography system was used for photography. The images were split into the training set (195 images), test set (120 images) and validation set (378 images).

A machine learning model, a convolutional neural network, was developed in the Python programming language using the Keras deep learning library. The model was trained with the images of the training set. After completion of training, the model was evaluated on the test set of images.

Results: Evaluation of the model on the test set produced a sensitivity of $97.87 \%$, specificity $85.26 \%$, PPV 95.18\%, NPV 93.10\% In 06 images, the model has failed to detect singly scattered malignant cells/ clusters. 14 (3.7\%) false positives was reported by the model.

The machine learning model shows potential utility as a screening tool. However, it needs improvement in detecting singly scattered malignant cells and filtering inflammatory infiltrate. 


\section{Introduction}

Ascitic fluid cytology is one of the first tests conducted in a patient with ascites, both for confirmation of a suspected malignancy and staging of a known malignancy. The detection of malignant cells in ascitic fluid is carried out by the pathologist by light microscopic examination. The sensitivity of this method in in detecting malignancy has been found to be $50 \%-96.7 \%$ in different studies. ${ }^{[1]}{ }^{[2]}{ }^{[3]}{ }^{[4]}$ One large case series found that ovarian malignancy is the only malignancy yielding a significant rate of detection from ascitic fluid cytology. ${ }^{[1]}$ There is a significant proportion of cases which are reported either false positive of false negative in ascitic fluid cytology. In one study of 170 patients, peritoneal cytology showed false negative results in $30.02 \%$ cases, while in $6.38 \%$ the results were false positive. ${ }^{[3]}$ This large variability in accuracy may be attributable to the often sparse and uneven distribution of malignant cell clusters in the smear. Thus screening slides for malignant cells is often a time consuming and error prone process. In one study, the false-negative were attributed to sampling errors in $71 \%$ of pleural and $73 \%$ of peritoneal effusions and to screening errors in $29 \%$ and $27 \%$, respectively. ${ }^{[4]}$ Immunostains for epithelial markers such as B72.3, MOC-31, and Ber-EP4 have been suggested for easy identification of such malignant clusters and also to confirm their epithelial origin. ${ }^{[5]}$ Preparation of cell blocks add $10-15 \%$ to the diagnostic sensitivity of body fluid cytology. ${ }^{[6]}{ }^{[7] .}$. In addition, immunohistochemical markers such as CEA significantly enhance the diagnostic efficacy: a combination of calretinin negative and CEA positive staining showed $97 \%$ sensitivity and $100 \%$ specificity for malignancy in one study of 50 cell blocks. ${ }^{[8]}$ But in a large case series of 5.5 years, it was also shown that use of IHC markers produces a higher rate of indeterminate but not malignant diagnosis ${ }^{[9]}$, thus undermining the utility of IHC.

Artificial neural networks (ANNs) are a large family of trainable models, where each subfamily of models is optimized for different functions. We have chose the ANN subfamily, known as convolutional neural networks (CNNs) which are shown to perform image-based object classification. ${ }^{[10]} \mathrm{CNNs}$ take a whole image as input and classifies the image in defined categories. The input image is passed through multiple "layers", each layer comprising multiple linear convolutional filters. ${ }^{[1]}$ The input for each layer is the output of the previous one, with an overlaid non-linearity. The image "features" extracted by the layers are finally fed into a classifier that determines the category the image belongs to. CNNs have been described by Karpathy et al. ${ }^{[12]}$

Deep, multilayered CNNs have been successful in recognising everyday objects ${ }^{[11,13]}$ and classifying them in correct categories ${ }^{[14]}$. We have aimed to apply the principles of CNNs to identify malignant cell clusters from ascitic fluid cytology smears. The model should be able to correctly identify malignant cell clusters from microphotographs of ascitic fluid cytology smears, 
and present them to the pathologist for review. The proportion of false negatives and false positives will have to be kept at a minimum. The model would serve as a pathologist assistant and a screening tool, and present foci of clusters identified as 'malignant' to the pathologist for review.

\section{Materials and methods}

Cases were selected from the archives of two hospitals. May Grunwald Giemsa stained Ascitic fluid/ pleural fluid cytology smears were included from 21 cases (14 malignant, 07 benign) in this study. All 14 malignant cases were confirmed by histopathology (except the one case of carcinoma of unknown primary site). The presence of malignant epithelial cells in ascitic/ pleural fluid were confirmed independently by two pathologists.

A total of 693 microphotographs were captured at 40x magnification at the same illumination and after correction of white balance. The foci were manually chosen as to represent well defined benign or malignant cells, and reviewed by two independent pathologists. A Magnus Integrated Microphotography system was used for photography. The photographed images were of $1280 \mathrm{x}$ 960 pixels in resolution.

The images were split into two subsets (Table 1).

1. a training set - for training of the machine learning model (i.e. learn the points of difference between appearance of benign and malignant cells in cytology)

2. a test set - for concurrent performance evaluation during training

3. a validation set - to evaluate the performance of the model after completion of training

Table 1: Distribution of images in training, test and validation set

\begin{tabular}{|l|l|l|l|}
\hline & Train & Test & Validation \\
\hline Benign & 45 & 20 & 95 \\
\hline Malignant & 150 & 100 & 283 \\
\hline Total & 195 & 120 & 378 \\
\hline
\end{tabular}

The machine learning model was developed in the Python programming language using the Keras deep learning library. A multilayered deep convolutional neural network (CNN) was developed using successive layers of convolutions, rectified linear unit (ReLu) and fully connected layers. The CNN takes an color image 256 x 192 pixels in dimension, and produces an output '0' (corresponding to benign) and ' 1 ' (malignant). The architecture of the CNN is shown in Figure 1. 


\begin{tabular}{|c|c|c|}
\hline Layer (type) & Output Shape & Param \# \\
\hline conv2d_9 (Conv2D) & $(32,254,190)$ & 896 \\
\hline activation_13 (Activation) & $(32,254,190)$ & $\odot$ \\
\hline max_pooling2d_9(MaxPooling2 & $(32,127,95)$ & $\odot$ \\
\hline conv2d_10 (Conv2D) & $(32,125,93)$ & 9248 \\
\hline activation_14 (Activation) & $(32,125,93)$ & $\Theta$ \\
\hline max_pooling2d_10 (MaxPooling & $(32,62,46)$ & $\odot$ \\
\hline conv2d_11 (Conv2D) & $(64,60,44)$ & 18496 \\
\hline activation_15 (Activation) & $(64,60,44)$ & $\odot$ \\
\hline max_pooling2d_11 (MaxPooling & $(64,30,22)$ & $\theta$ \\
\hline conv2d_12 (Conv2D) & $(64,28,20)$ & 36928 \\
\hline activation_16 (Activation) & $(64,28,20)$ & 0 \\
\hline max_pooling2d_12 (MaxPooling & $(64,14,10)$ & 0 \\
\hline flatten_3(Flatten) & $(8960)$ & $\odot$ \\
\hline dense_5 (Dense) & $(64)$ & 573504 \\
\hline activation_17 (Activation) & $(64)$ & $\odot$ \\
\hline dropout_3 (Dropout) & $(64)$ & $\odot$ \\
\hline dense_6 (Dense) & (1) & 65 \\
\hline $\begin{array}{l}\text { activation_18 (Activation) } \\
\text { ======================== } \\
\text { Total params: } 639,137 \\
\text { Trainable params: } 639,137 \\
\text { Non-trainable params: } \odot\end{array}$ & $=\underline{(1)}=$ & =シேニ=ニ=ニ=ニ=ニ=ニ=- \\
\hline
\end{tabular}

Figure 1: Architecture of the Convolutional Neural Network

Images were resized to $256 \times 192$ pixels before training. The CNN was trained several times with the images of the training set, with varying number of epochs; an optimal training with 10 epochs of and 200 steps per epoch was chosen (Figure 2) which maximised the diagnostic accuracy. Over the period of training, the $\mathrm{CNN}$ adjusted its parameters to produce the correct output in majority of cases. During training, $93.75 \%$ accuracy was achieved on the testing set. The loss function (error rate) showed gradual decline over both training and test set. (Figure 3-4)

After completion of training, the performance of the model on the validation set of images was evaluated using standard statistical methods. 
bioRxiv preprint doi: https://doi.org/10.1101/2021 07.20.453010; this version posted July 22, 2021. The copyright holder for this preprint (which was not certified by peer review) is the author/funder, who has granted bioRxiv a license to display the preprint in perpetuity. It is made available under aCC-BY 4.0 International license.

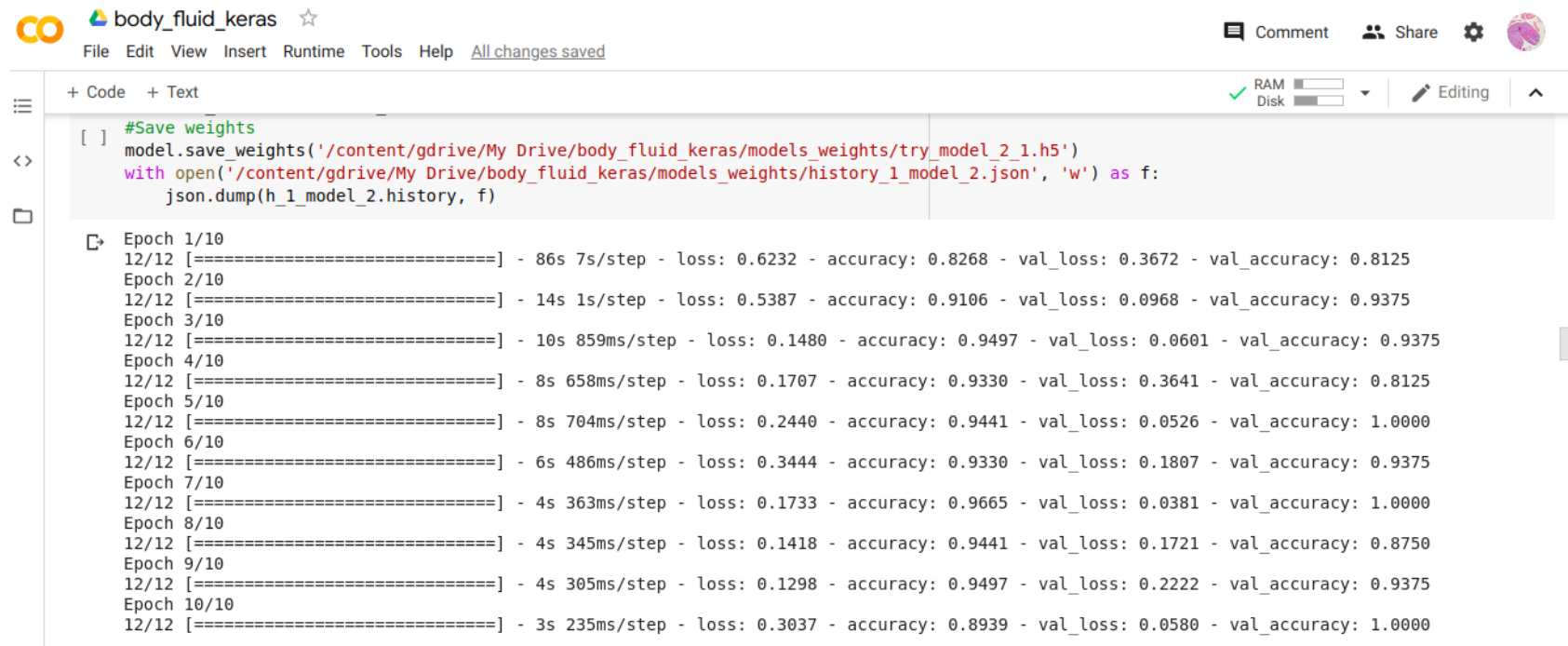

Figure 2: Training session of the model

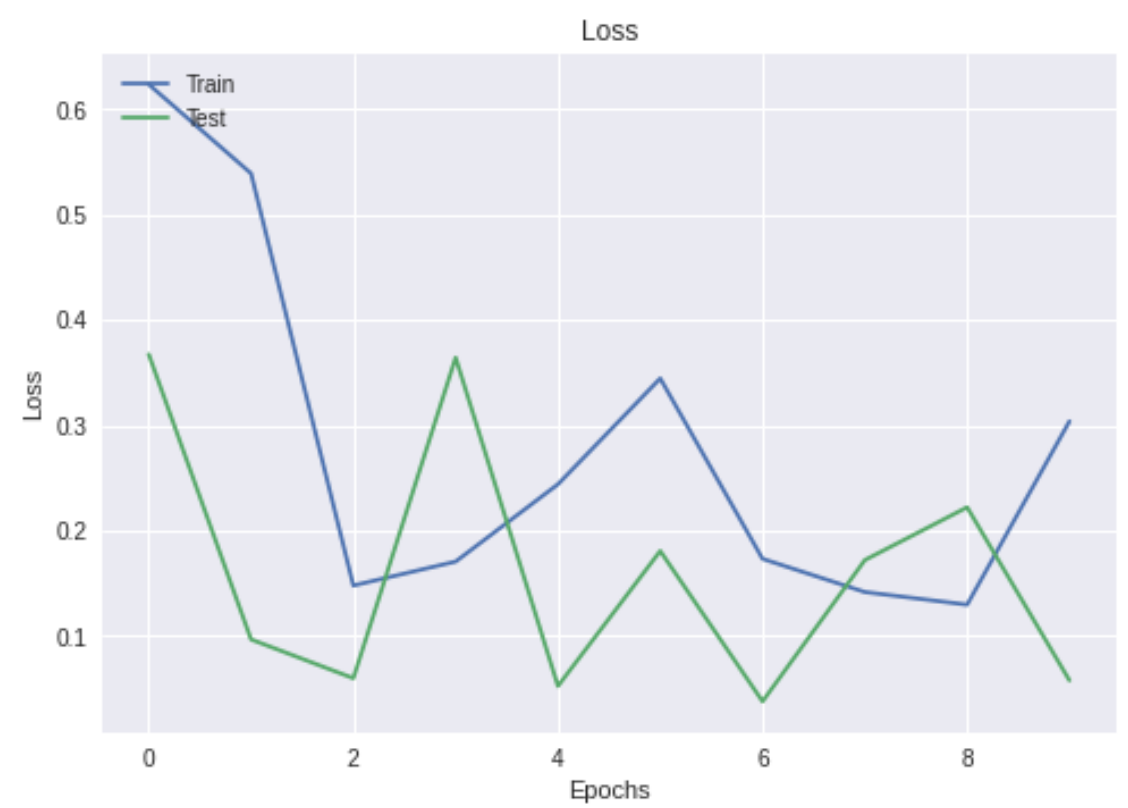

Figure 3: Loss function (error rate) plotted versus epochs of training 


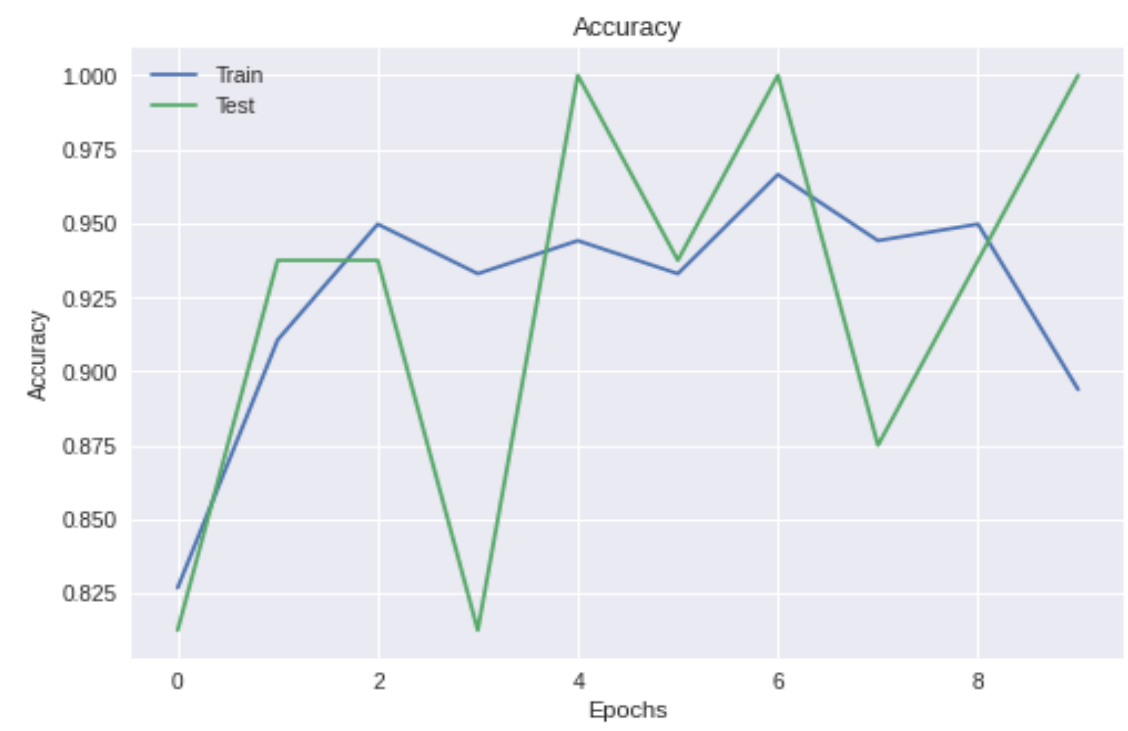

Figure 4: Accuracy of the model plotted versus epochs of training

\section{Results}

Evaluation of the model on the test set produced $97.87 \%$ sensitivity, $85.26 \%$ specificity, $95.18 \%$ positive predictive value (PPV) and $93.10 \%$ negative predictive value (NPV). The model successfully classified majority of benign foci. Only 06 false negatives and 14 false positive was reported (Table 2).

Table 2: Performance of the model on the validation set

\begin{tabular}{|l|l|l|l|}
\hline & Actual & & \\
\hline & Benign & Malignant & Total \\
\hline Predicted & & & \\
\hline Benign & 81 & 6 & 87 \\
\hline Malignant & 14 & 277 & 291 \\
\hline Total & 95 & 283 & 378 \\
\hline Sensitivity & $97.87 \%$ & Specificity & $85.26 \%$ \\
\hline PPV & $95.18 \%$ & NPV & $93.10 \%$ \\
\hline
\end{tabular}

In $06(1.5 \%)$ images, the model has failed to detect malignant cells; all of these images were paucicellular. Possible over-fitting has resulted in 14 false positive images; in 11 of these images, a hemorrhagic background seems to have interfered with correct classification. (Figure 5-8) 
bioRxiv preprint doi: https://doi org/10.1101/2021.07.20.453010; this version posted July 22, 2021. The copyright holder for this preprint (which was not certified by peer review) is the author/funder, who has granted bioRxiv a license to display the preprint in perpetuity. It is made available under aCC-BY 4.0 International license.

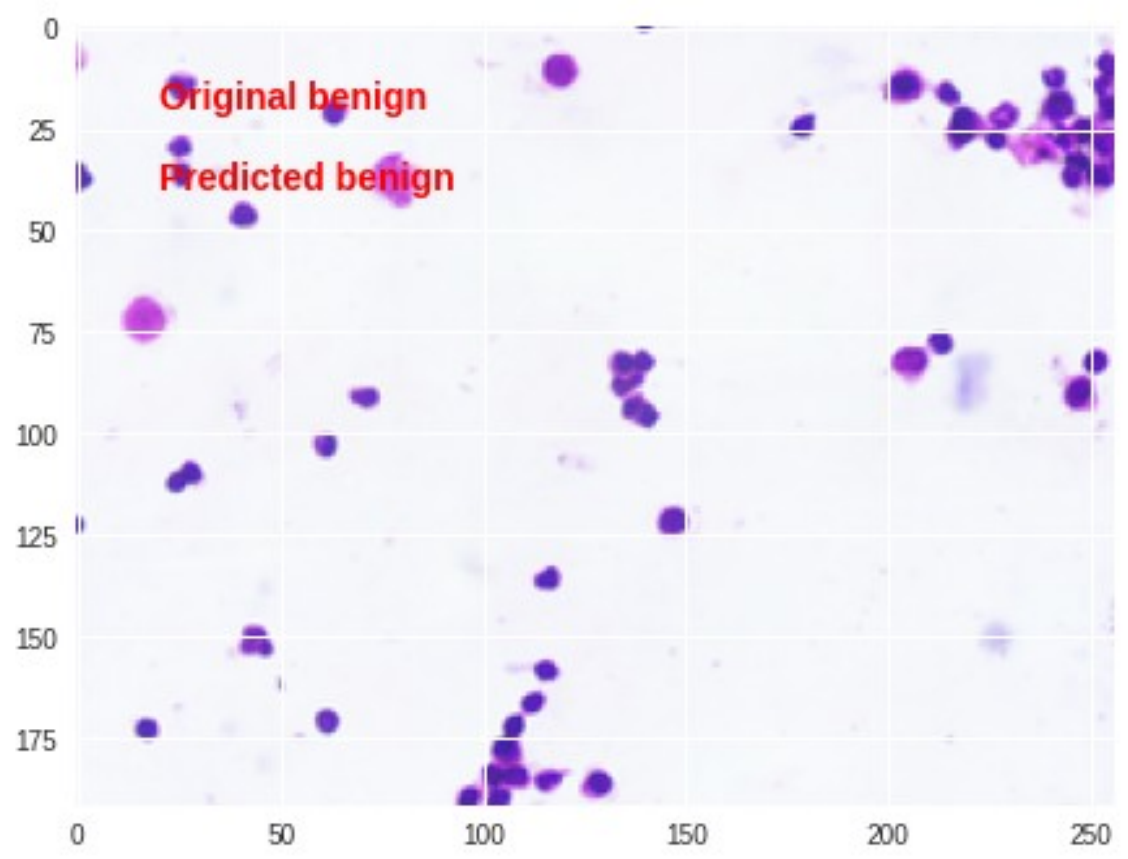

Figure 5: Correct classification by the model

The results demonstrate that the model is capable of correctly classifying majority of foci in benign or malignant categories. A rare mesothelial cell cluster has been labeled malignant (Figure 9). The model has demonstrated the ability to detect malignant cells from a densely inflammatory background (Figure 10). However, difficulties remain where cellularity is low and malignant cells

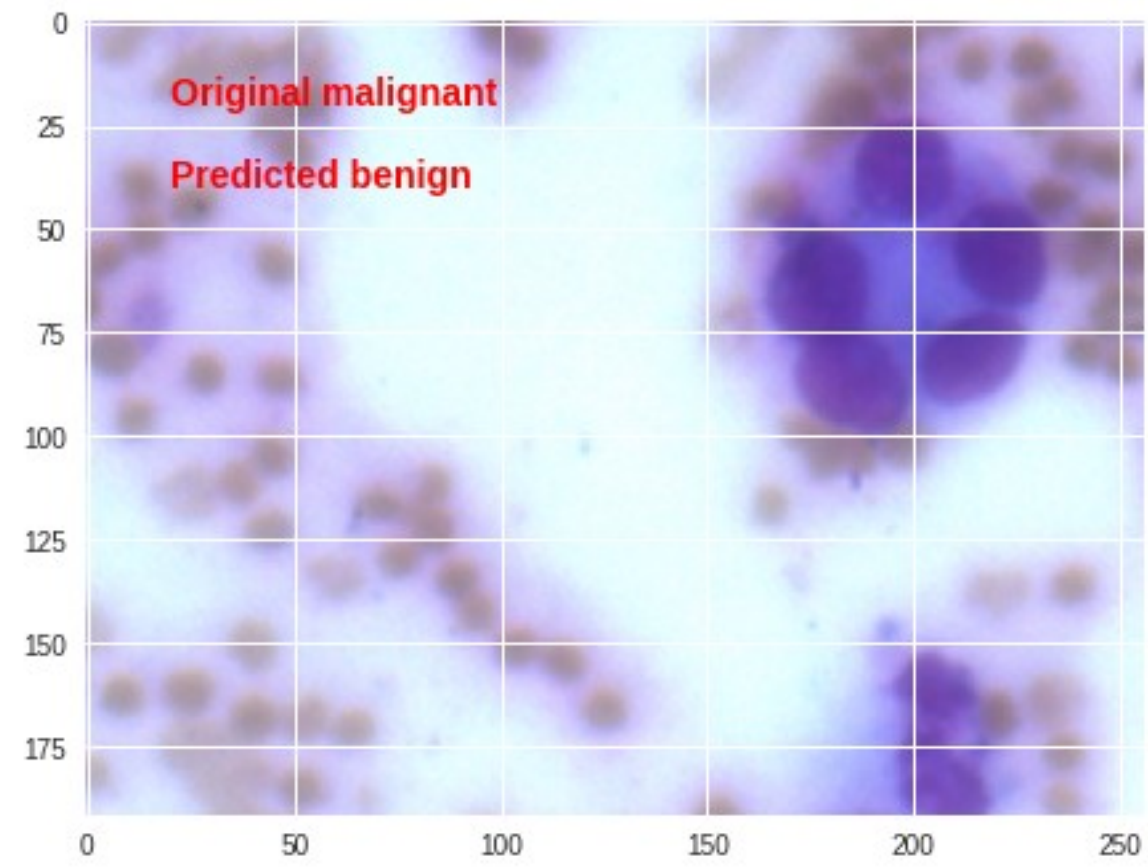

Figure 6: The model has missed the single cluster of malignant cells 
bioRxiv preprint doi: https://doi. org/10.1101/2021.07 20.453010; this version posted July 22, 2021. The copyright holder for this preprint (which was not certified by peer review) is the author/funder, who has granted bioRxiv a license to display the preprint in perpetuity. It is made available under aCC-BY 4.0 International license.

are present in small isolated clusters. Also, a hemorrhagic background can obscure malignant cells.

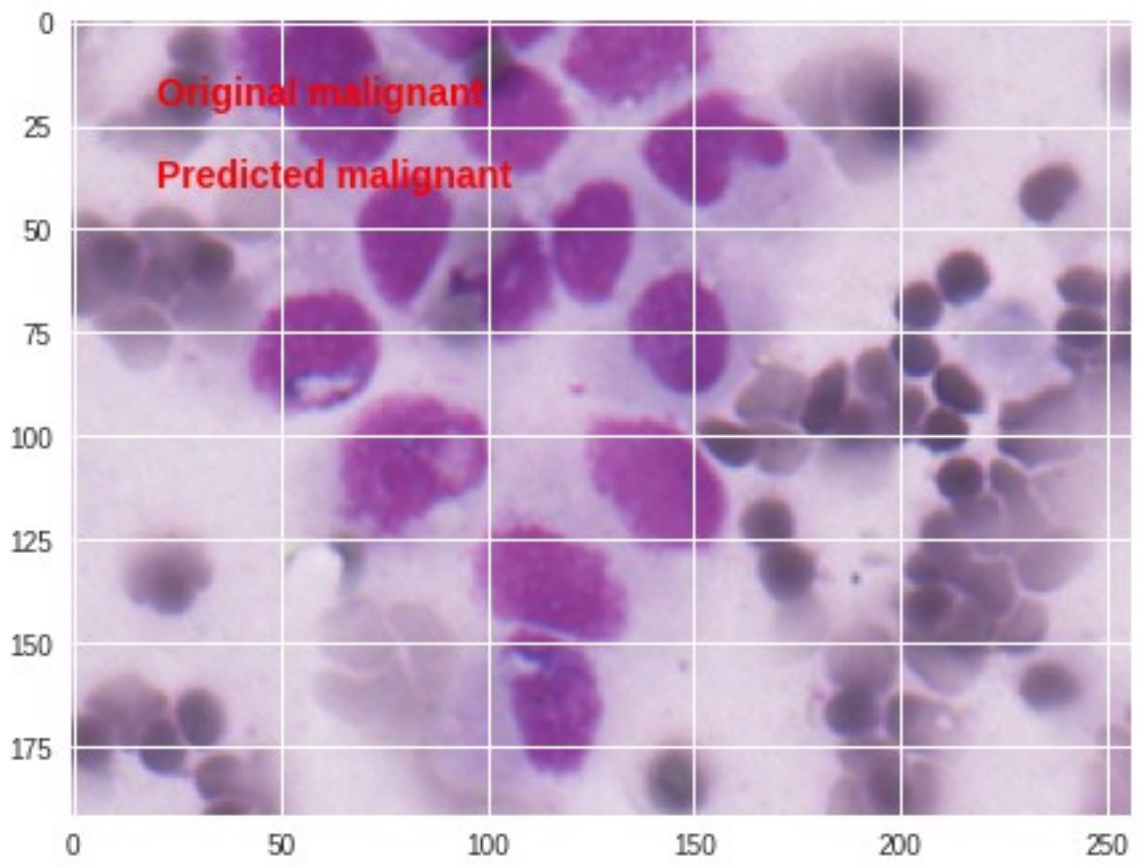

Figure 7: Malignant cell cluster correctly identified by the model

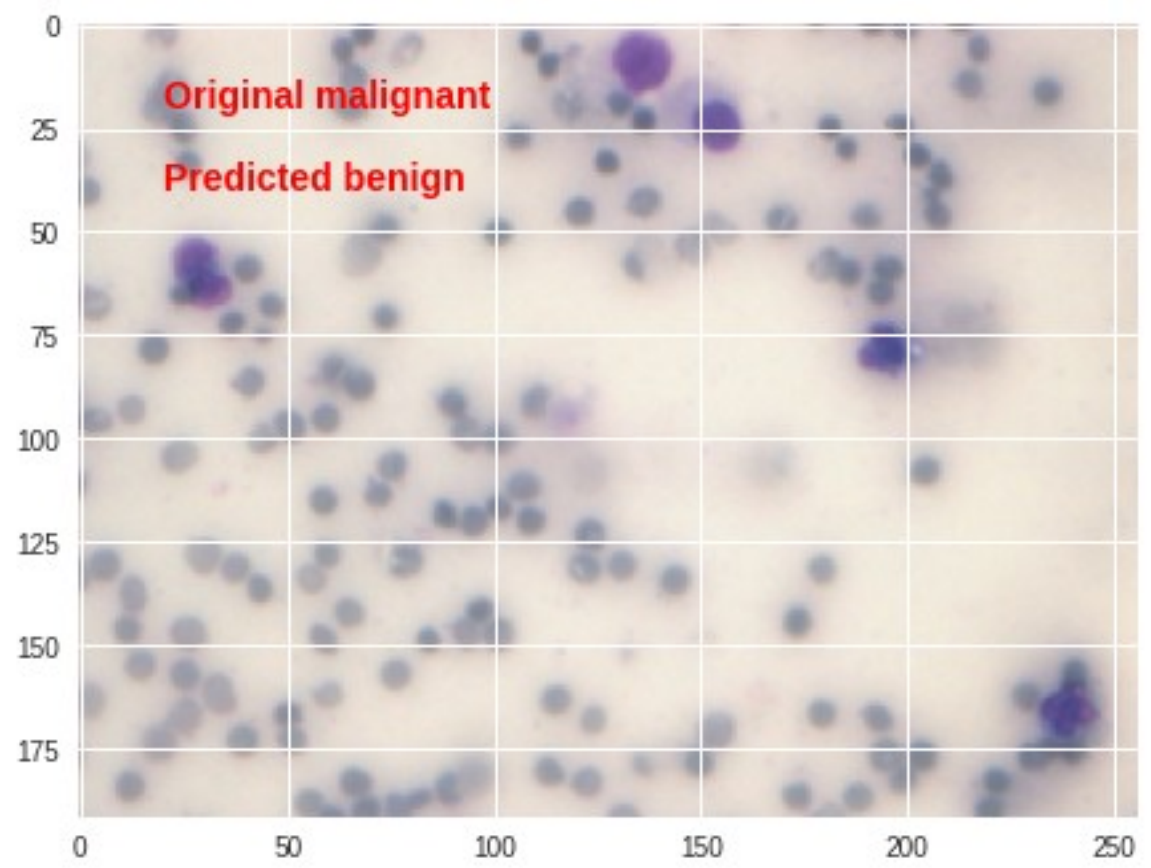

Figure 8: Paucity of cells have interfered with the identification of malignant cells in this focus 
bioRxiv preprint doi: https://doi.org/10.1101/2021.07.20.453010; this version posted July 22,2021 . The copyright holder for this preprin (which was not certified by peer review) is the author/funder, who has granted bioRxiv a license to display the preprint in perpetuity. It is

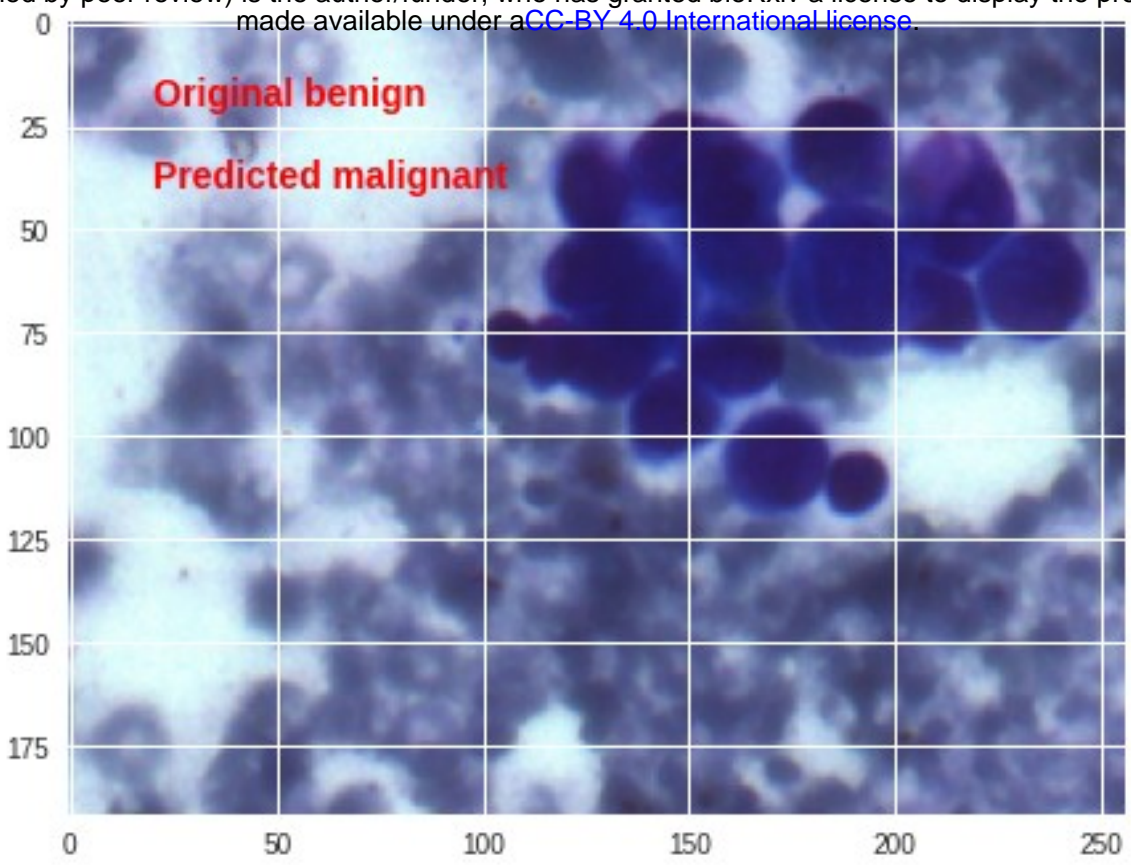

Figure 9: Mesothelial cell clusters wrongly classified as malignant, over a hemorrhagic background

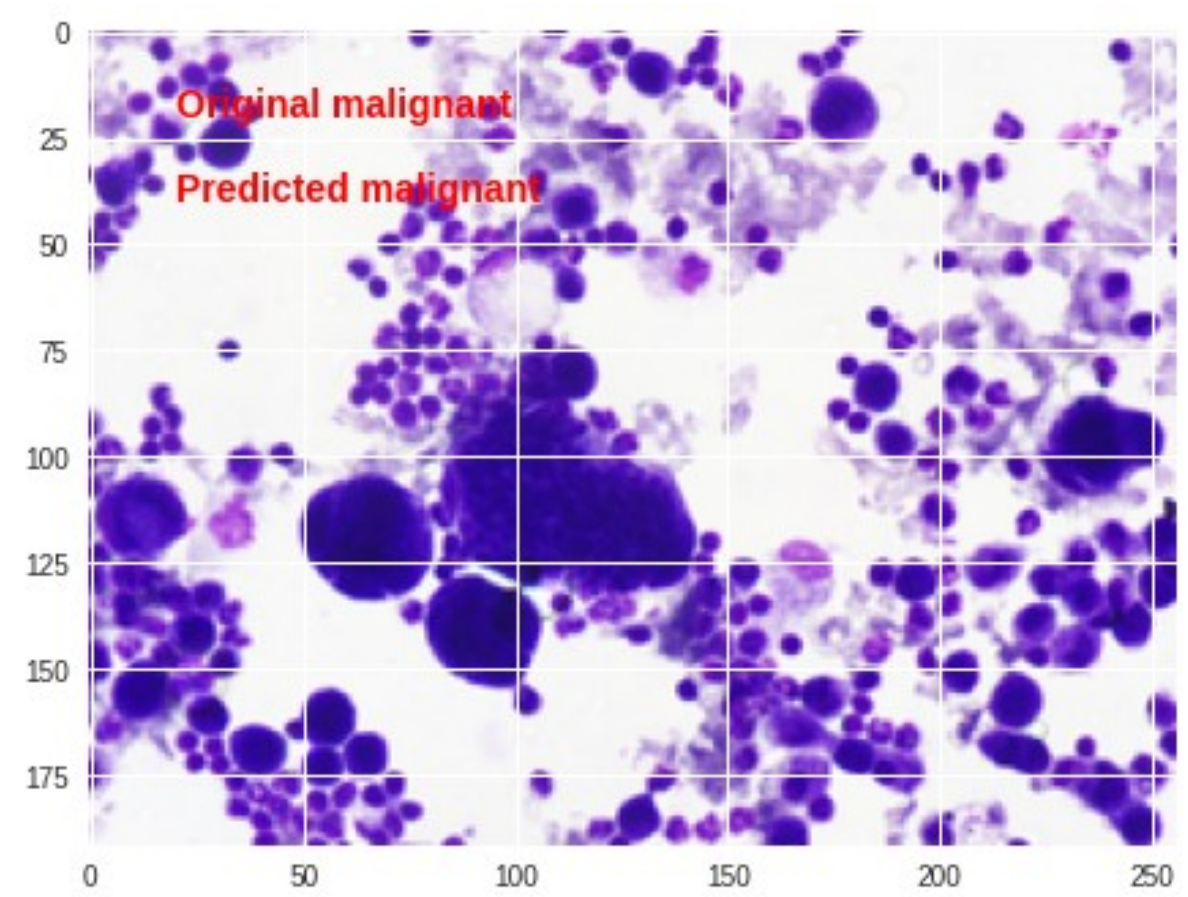

Figure 10: Malignant cells detected over an inflammatory background

Analysis of receiver operating characteristics of the model showed area under curve (AUC) to be 0.916, which is the diagnostic accuracy of the model (Figure 11). 


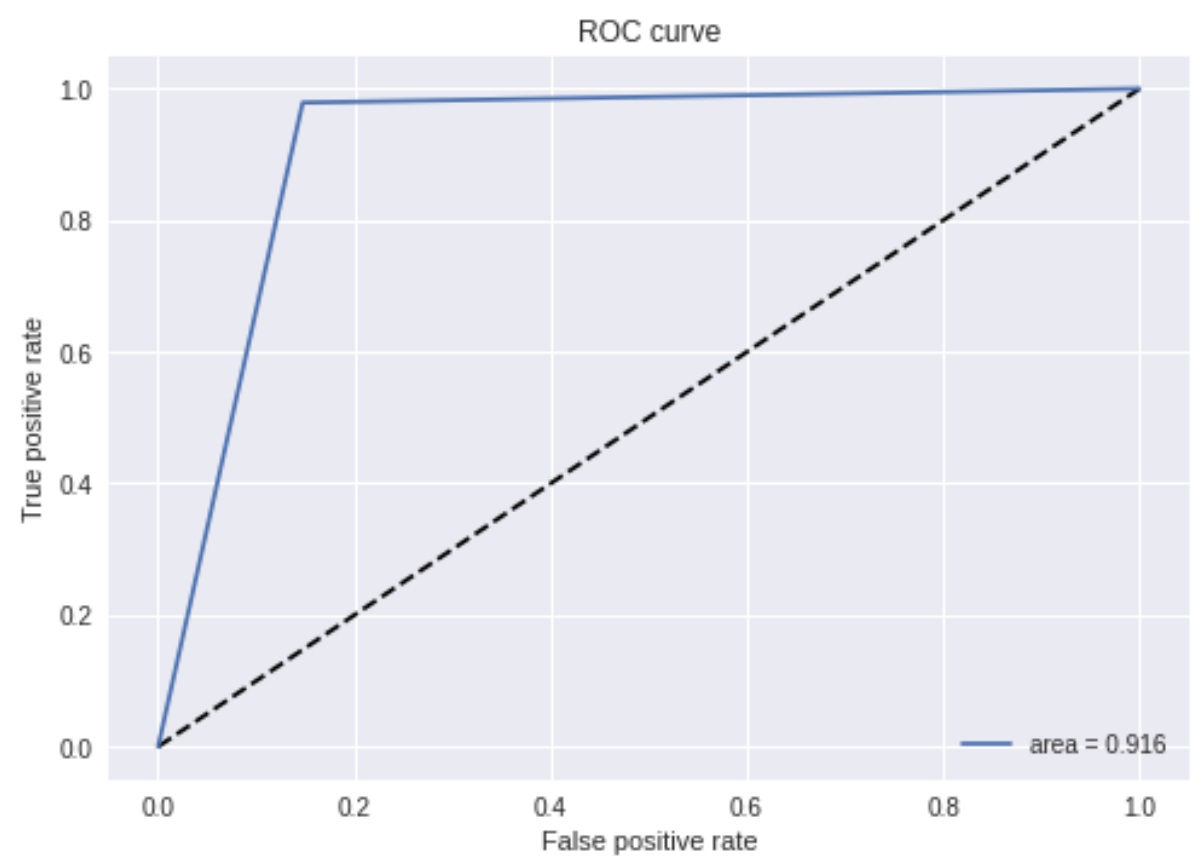

Figure 11: Receiver operating characteristics (ROC) of the model

\section{Discussion}

Whereas microscopy on direct MGG stained smears is the traditionally accepted method, it suffers from the drawbacks of low sensitivity and variable inter-observer reproducibility. Cell block preparation and IHC have been found to be of optimal value in only $10-12 \%$ of fluids (in a population with relatively low prevalence of malignancy), above which their diagnostic utility diminishes. ${ }^{[9]}$ The sensitivity and specificity of IHC in detection of malignancy in body fluid has yet not exceeded $90 \%{ }^{[20]}{ }^{[21]}$

Artificial neural networks have emerged as a useful decision support tool in cytopathology. ${ }^{[15]}$ Pathologist's assistant machine learning models have been developed for cervical ${ }^{[16]}{ }^{[17]}$ and thyroid ${ }^{[18]}{ }^{[19]}$ cytology. The present study aims to develop such a model for recognising malignant cells from body fluid cytology smears.

There have been few studies regarding such automated decision systems on body fluid cytology. There has been focus in extracting geometric features from the image and applying machine learning models over the extracted features. For example, Win et al used extracted features from the image and used them as inputs for an artificial neural network. On a sample of 125 images, their method achieved sensitivity of $87.97 \%$, specificity of $99.40 \%$, with $98.70 \%$ diagnostic accuracy. [22] Baykal et al used the technique of active appearance model for to achieve effective cell segmentation from cytopathological images, with good diagnostic accuracy. ${ }^{[23]}$ The wavelet transform has also been shown to achieve a high recognition ratio. ${ }^{[24]}$ Zhang et al have used morphometric parameters (area rate of the karyon and cytoplasm, the optic density, the shape 
factor) and used these parameters with a fuzzy pattern recognition model to detect cancer cells. ${ }^{[25]}$ In a related study, while analysing the difference between malignant and benign mesothelial cell proliferations, Tosun et al found that the quantification of chromatin distribution is $100 \%$ predictive of whether a cell is malignant. ${ }^{[26]}$

We have not extracted any geometric feature from images, because we have included images from a variety of foci from which such morphometry is not possible. Our study sample has included smears with eosinophilic material rich background, few foci with dense inflammatory infiltrate, and also few foci with very sparse malignant cells. Keeping all this variation in mind, we have used the entire image as input to the neural network. This method, however, has yielded $97 \%$ sensitivity (on individual foci), albeit with moderate specificity (85\%).

A subset of the intermediate layers of the neural network as it processes an image is shown in Figure 12. The image is simplified and filtered over the layers of the network, to finally produce an output of 0 or 1 . It is interesting to note how a certain future of an image gets highlighted and extracted over several convolutions and transformations through the layers of the network.

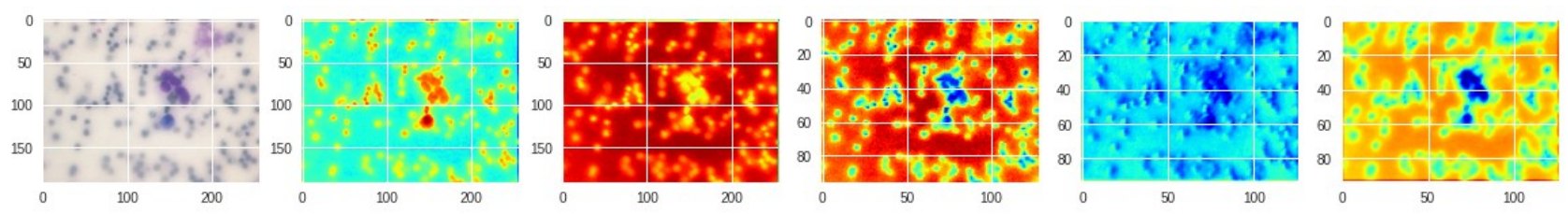

Figure 12: Processing an image through the intermediate layers of the CNN

It is important to recognize the limitations of this model: hemorrhagic background has been shown to interfere with its functioning (Figure 9), and it has failed to recognize two foci of sparse malignant cells (Figure 10). The study was performed with a limited number of samples to develop a prototype machine learning model. Further refinement in technique and training with a greater number of images are required.

\section{Conflicts of interest}

None to declare

\section{Data availability}

Image dataset and code are available at https://github.com/vaishleshik/body fluid classifier.

\section{Fundings}

No external funding was received for this study 
bioRxiv preprint doi: https://doi org/10.1101/2021.07.20.453010; this version posted July 22, 2021. The copyright holder for this preprint (which was not certified by peer review) is the author/funder, who has granted bioRxiv a license to display the preprint in perpetuity. It is made available under aCC-BY 4.0 International license.

\section{Note}

Sayak Paul made his contribution while employed at PyImageSearch

\section{References}

1. How valuable is ascitic cytology in the detection and management of malignancy? | Postgraduate Medical Journal [Internet]. [cited 2019 Jul 5];Available from: https://pmj.bmj.com/content/79/931/292

2. Runyon BA, Hoefs JC, Morgan TR. Ascitic fluid analysis in malignancy-related ascites. Hepatology 1988;8(5):1104-9.

3. Živadinović R, Petrić A, Krtinić D, Stevanović Milosević J, Pop Trajković Dinić S. Ascites in Ovarian Carcinoma - Reliability and Limitations of Cytological Analysis. West Indian Med J 2015;64(3):236-40.

4. Motherby H, Nadjari B, Friegel P, Kohaus J, Ramp U, Böcking A. Diagnostic accuracy of effusion cytology. Diagn Cytopathol 1999;20(6):350-7.

5. Lin O. Challenges in the Interpretation of Peritoneal Cytologic Specimens. Arch Pathol Lab Med 2009;133(5):739-42.

6. Bhanvadia Viral M, Santwani P, Vachhani J. Analysis of Diagnostic Value of Cytological Smear Method Versus Cell Block Method in Body Fluid Cytology: Study of 150 Cases. Ethiop J Health Sci 2014;24(2):125-31.

7. Shivakumarswamy U, Arakeri SU, Karigowdar MH, Yelikar B. Diagnostic utility of the cell block method versus the conventional smear study in pleural fluid cytology. J Cytol Indian Acad Cytol 2012;29(1):11-5.

8. Yahya ZM, Ali HH, Hussein HG. Evaluation of the Sensitivity and Specificity of Immunohistochemical Markers in the Differential Diagnosis of Effusion Cytology. Oman Med J 2013;28(6):410-6.

9. Alshaikh S, Lapadat R, Atieh MK, Mehrotra S, Barkan GA, Wojcik EM, et al. The utilization and utility of immunostains in body fluid cytology. Cancer Cytopathol 2020;128(6):384-91.

10. He K, Zhang X, Ren S, Sun J. Deep Residual Learning for Image Recognition. ArXiv151203385 Cs [Internet] 2015 [cited 2018 Nov 12];Available from: http://arxiv.org/abs/1512.03385

11. Krizhevsky A, Sutskever I, Hinton GE. ImageNet Classification with Deep Convolutional Neural Networks [Internet]. In: Proceedings of the 25th International Conference on Neural Information Processing Systems - Volume 1. USA: Curran Associates Inc.; 2012 [cited 2019 Jan 10]. page 1097-105.Available from: http://dl.acm.org/citation.cfm?id=2999134.2999257

12. CS231n Convolutional Neural Networks for Visual Recognition [Internet]. [cited 2019 Jan 10];Available from: http://cs231n.github.io/convolutional-networks/

13. ImageNet [Internet]. [cited 2019 Feb 13];Available from: http://www.image-net.org/

14. Redmon J, Farhadi A. YOLOv3: An Incremental Improvement. ArXiv180402767 Cs [Internet] 2018 [cited 2018 Nov 12];Available from: http://arxiv.org/abs/1804.02767 
15. Pouliakis A, Karakitsou E, Margari N, Bountris P, Haritou M, Panayiotides J, et al. Artificial Neural Networks as Decision Support Tools in Cytopathology: Past, Present, and Future. Biomed Eng Comput Biol 2016;7:1-18.

16. PAPNET-assisted rescreening of cervical smears: cost and accuracy compared with a $100 \%$ manual rescreening strategy. - PubMed - NCBI [Internet]. [cited 2019 Jul 5];Available from: https://www.ncbi.nlm.nih.gov/pubmed/9438746

17. Bengtsson E, Malm P. Screening for Cervical Cancer Using Automated Analysis of PAPSmears [Internet]. Comput. Math. Methods Med.2014 [cited 2018 Dec 12];Available from: https://www.hindawi.com/journals/cmmm/2014/842037/

18. Savala R, Dey P, Gupta N. Artificial neural network model to distinguish follicular adenoma from follicular carcinoma on fine needle aspiration of thyroid. Diagn Cytopathol 2017;46.

19. Sanyal P, Mukherjee T, Barui S, Das A, Gangopadhyay P. Artificial Intelligence in Cytopathology: A Neural Network to Identify Papillary Carcinoma on Thyroid Fine-Needle Aspiration Cytology Smears. J Pathol Inform 2018;9:43.

20. Dey. Utility of cell block to detect malignancy in fluid cytology: Adjunct or necessity? [Internet]. [cited $2021 \mathrm{Jul} 20$ ];Available from: https://www.cancerjournal.net/article.asp? issn $=0973-1482 ;$ year $=2017$; volume $=13 ;$ issue $=3 ;$ spage $=425 ;$ epage $=429 ;$ aulast $=$ Dey

21. Rekhi B, Karmarkar S, Gupta C, Deodhar KK, Menon S, Pathuthara S, et al. Evaluation of cell blocks from effusion specimens in Gynecologic Oncopathology: An experience of 220 cases, diagnosed at a Tertiary Cancer Referral Center. Indian J Pathol Microbiol 2020;63(3):427.

22. Win KY, Choomchuay S, Hamamoto K, Raveesunthornkiat M, Rangsirattanakul L, Pongsawat S. Computer Aided Diagnosis System for Detection of Cancer Cells on Cytological Pleural Effusion Images [Internet]. BioMed Res. Int.2018 [cited 2019 Jul 4];Available from: https://www.hindawi.com/journals/bmri/2018/6456724/

23. Baykal E, Dogan H, Ekinci M, Ercin ME, Ersoz S. Automated Cell Nuclei Segmentation in Pleural Effusion Cytology Using Active Appearance Model. In: Felsberg M, Heyden A, Krüger $\mathrm{N}$, editors. Computer Analysis of Images and Patterns. Springer International Publishing; 2017. page 59-69.

24. Fuhua Chen, Jun Xie, Hong Zhang, Deshen Xia. A technique based on wavelet and morphology transform to recognize the cancer cell in pleural effusion. In: Proceedings International Workshop on Medical Imaging and Augmented Reality. 2001. page 199-203.

25. Zhang L, Wang Q, Qi J. Research Based on Fuzzy Algorithm of Cancer Cells in Pleural Fluid Microscopic Images Recognition. In: 2006 International Conference on Intelligent Information Hiding and Multimedia. 2006. page 211-4.

26. Detection of malignant mesothelioma using nuclear structure of mesothelial cells in effusion cytology specimens - Tosun - 2015 - Cytometry Part A - Wiley Online Library [Internet]. [cited 2019 Jul 5];Available from: https://onlinelibrary.wiley.com/doi/full/10.1002/cyto.a.22602 